\title{
HEART BLOCK IN OSTEITIS DEFORMANS
}

\author{
BY \\ C. V. HARRISON AND BERNARD LENNOX \\ From the Department of Morbid Anatomy, British Postgraduate Medical School
}

Received June 1, 1948

The simian figure of the country gentleman from the north of England, who was Sir James Paget's first reported case (1877) of osteitis deformans, hobbles still through all accounts of this disease: he exemplifies most of the known complications. Paget himself learnt little more from the twenty-two other cases he saw $(1882,1889)$, and since then a forest of at least 700 articles, covering over 2000 cases, has added little wholly new to the original description.

The basic problem of the ætiology still eludes us. Schmorl $(1926,1930,1932)$ has shown the disease to be less rare than Paget thought, and with many others (Higbee and Ellis, 1911; Knaggs, 1926; and Jaffe, 1933, the chief) has extended our knowledge of the morbid anatomy. Da Costa et al. (1915) questioned, and Koller (1946) seems to have refuted, Paget's denial of all hereditary element. Packard et al. (1901) and Knaggs (1926) questioned, but Coley and Sharpe (1931) established beyond question, Paget's claim of a relationship to bone sarcoma. Of perhaps more fundamental importance are the demonstrations, by methods not available to Paget, of the high blood phosphatase by Kay (1930) and of the extraordinarily high blood flow through affected bones by Edholm, Howarth, and McMichael (1945).

The interest in the vascular relations of the disease following the latter work encourages us to report two cases of a complication that has so far been overlooked. In both cases calcification of the interventricular septum, consequent we believe upon the Paget's disease, interrupted the bundle of $\mathrm{His}$ and produced heart block. This seems to be no coincidence: a recent series (Windholz and Grayson, 1947) of 12 cases of heart block (in all of which septal calcification was demonstrated radiologically) included 2 cases of Paget's disease.

\section{CASe Notes}

Case 1. An unmarried woman of 71 who worked as a chambermaid was admitted under the care of
Dr. Paul Wood in January 1936. She stated that since youth she had suffered from pains in her legs. In 1919 , at the age of 54 , this pain became much worse and her legs became bowed, and at the same time her left clavicle enlarged. She was able to get about with difficulty but continued working for two years, after which she was only able to move with crutches. The disease progressed and when admitted in 1936 she was quite unable to get about. On examination she showed the typical picture of Paget's disease with bowing and thickening of both femora and tibiæ and the right ulna and clavicle. There was a hard mass in the connective tissues just lateral to the crest of the left ilium. The skull and spine were not deformed. Skiagrams confirmed the diagnosis of Paget's disease and showed the subcutaneous mass to be calcarious. The blood count was within normal limits, blood calcium was $9 \cdot 2 \mathrm{mg}$. per $100 \mathrm{ml}$., blood phosphorus $9 \cdot 1 \mathrm{mg}$. per $100 \mathrm{ml}$., and blood phosphatase was 52 KingArmstrong units but later fluctuated between 60 and 70 units. The pulse was 80 , the B.P. $175 / 85$. The apex beat was forceful four and a half inches from the midline. There was a rough systolic murmur at the apex and a soft systolic murmur at the aortic area. She was transferred to the chronic block and about 18 months later began to have attacks of unconsciousness preceded by a sensation of fluttering in the abdomen. A cardiogram during these attacks showed complete heart block (Fig. 1) with a ventricular rate of 30 and an auricular rate of 120. Between attacks there was right bundle branch block. These Stokes-Adams attacks continued intermittently until December 1937 when she died in one.

Autopsy was carried out 39 hours after death. Advanced Paget's disease was seen in the right femur, tibia, clavicle, pelvis, and sternum. There was Paget's disease without significant deformity in the spine. There was no apparent disease in the ribs (Fig. 2), right fibula, skull, or left clavicle. Other bones were not excised. In the right clavicle 
the disease had progressed to almost ivory-like sclerosis but in all the other affected bones osteoporosis was in advance of sclerosis and the bones were soft and extremely vascular.
The mass in the subcutaneous tissues proved to be a focus of amorphous calcification $8 \times 6 \times 3 \mathrm{~cm}$. The heart weighed $585 \mathrm{~g}$. and showed muscular hypertrophy. The coronary arteries were injected

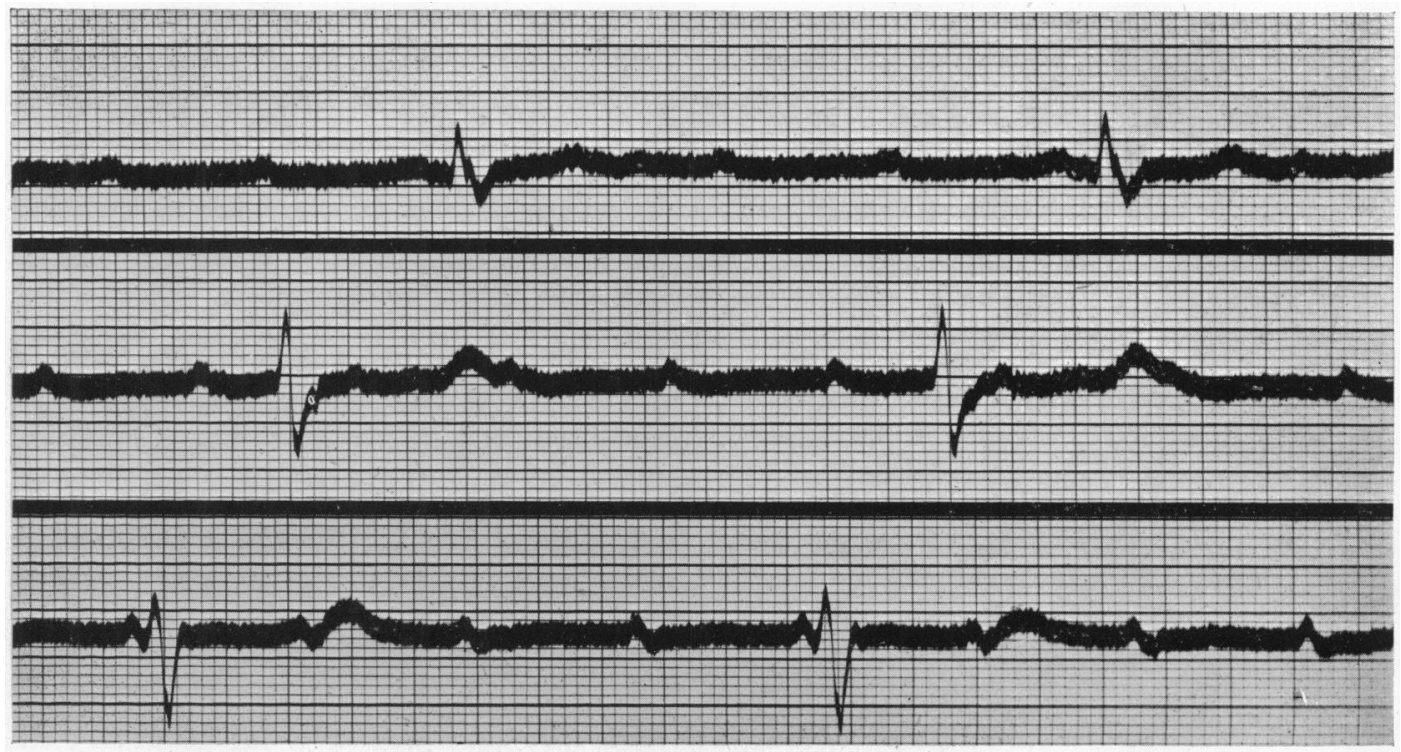

Fig. 1.-Case 1. Electrocardiogram during a Stokes-Adams attack.

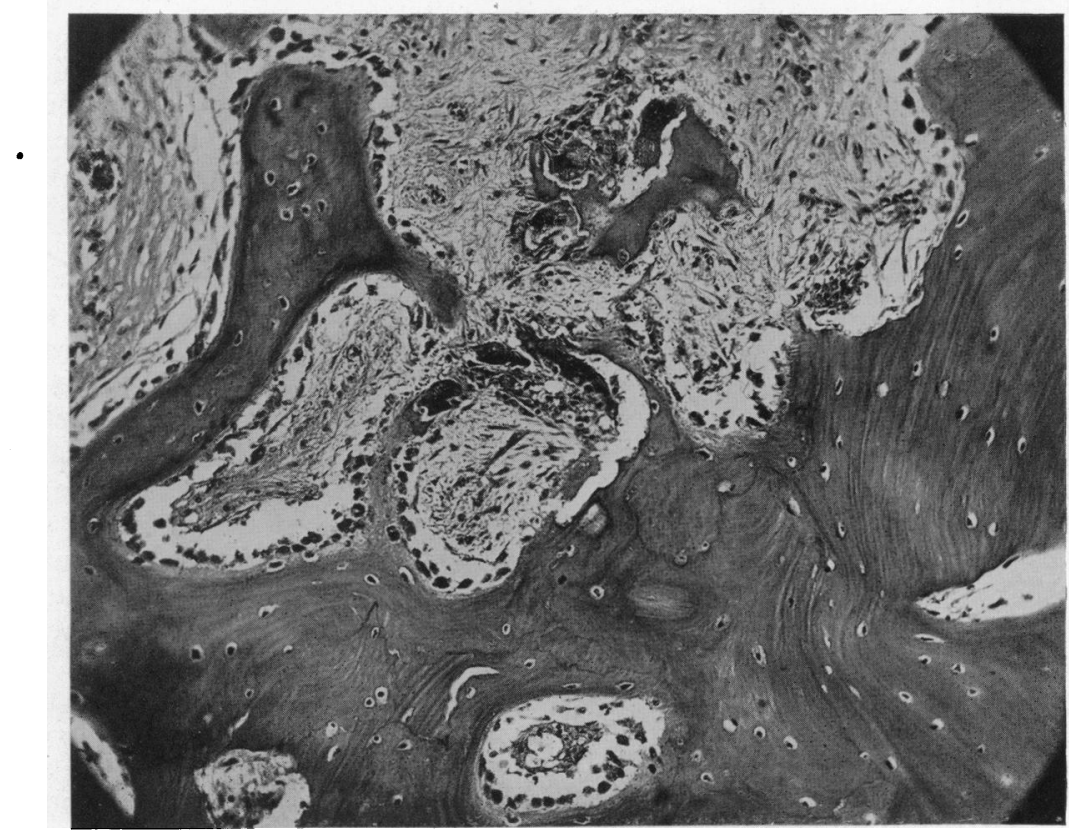

FIG. 2.-Case 1. Rib, showing osteoblastic and osteoclastic activity, vascular fibrous marrow, and irregular cement lines. Stained with H. and E. Magnification: $\times 112$. 
with barium gelatine mixture and skiagrams showed normal lumina. At the base of the mitral valve, in the connective tissues at its attachment, there was a bar of calcification extending the length of the posterior cusp and spreading on to the base of the interventricular septum to involve the pars membranacea septi (Fig. 3). Apart from this the mitral leaflets were healthy as were those of the other valves.

Microscopic section confirmed the gross findings. The calcification in the heart was amorphous and was surrounded by fibrosis. There was Mönckeberg sclerosis in the iliac artery. The kidneys did not show hypertensive changes and the degree of cardiac hypertrophy $(585 \mathrm{~g}$.) remained unexplained. In the light of Case 2, one is tempted to suggest that this too may have been an example of high output hypertrophy due to a vascular shunt through bones.

Case 2. An old-age pensioner, aged 74 , was admitted in October 1947 under Professor

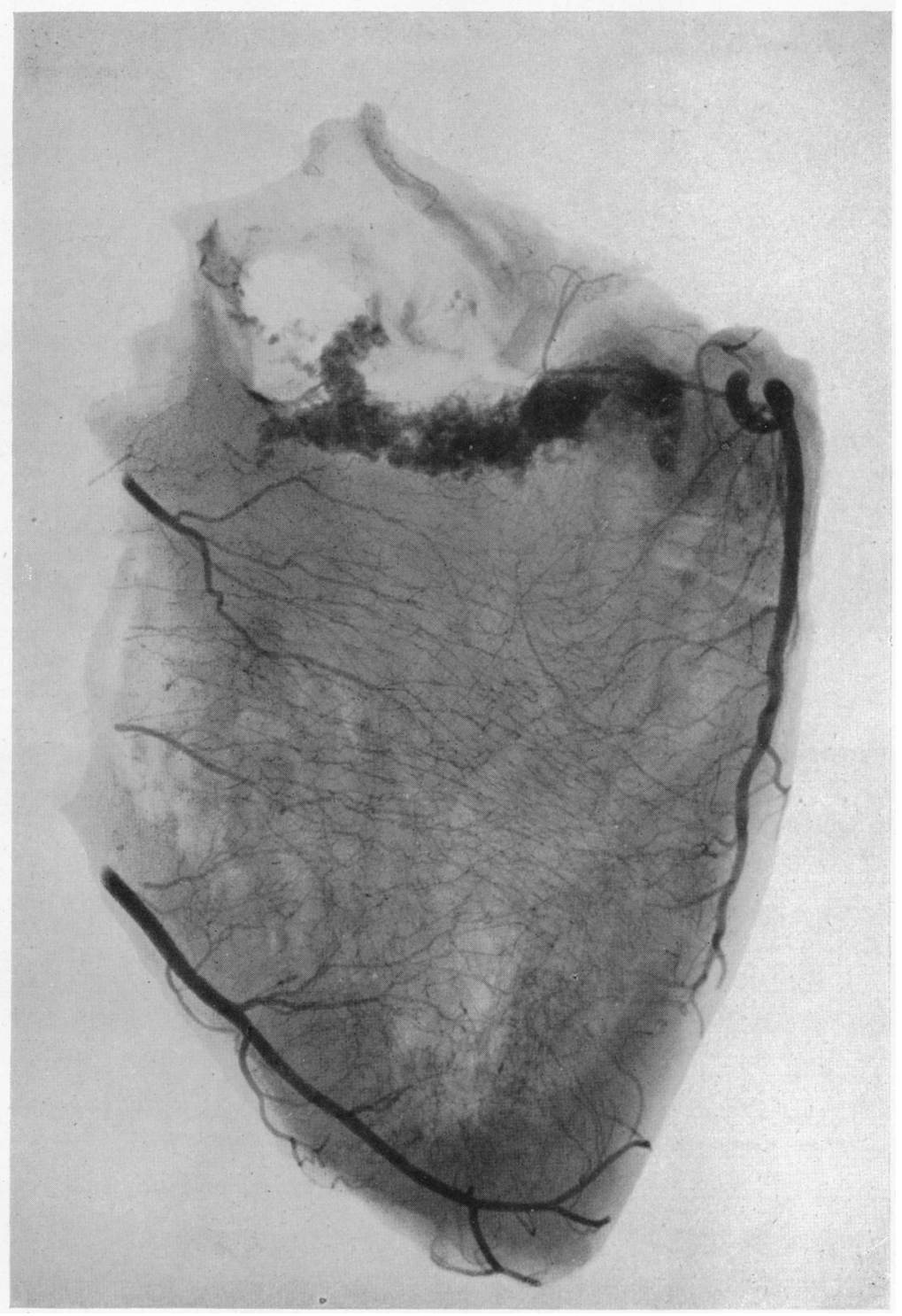

FIG. 3.-Case 1. X-ray of the septum after barium gelatine injection of vessels, showing the intact blood supply and calcification involving the pars membranacea. 


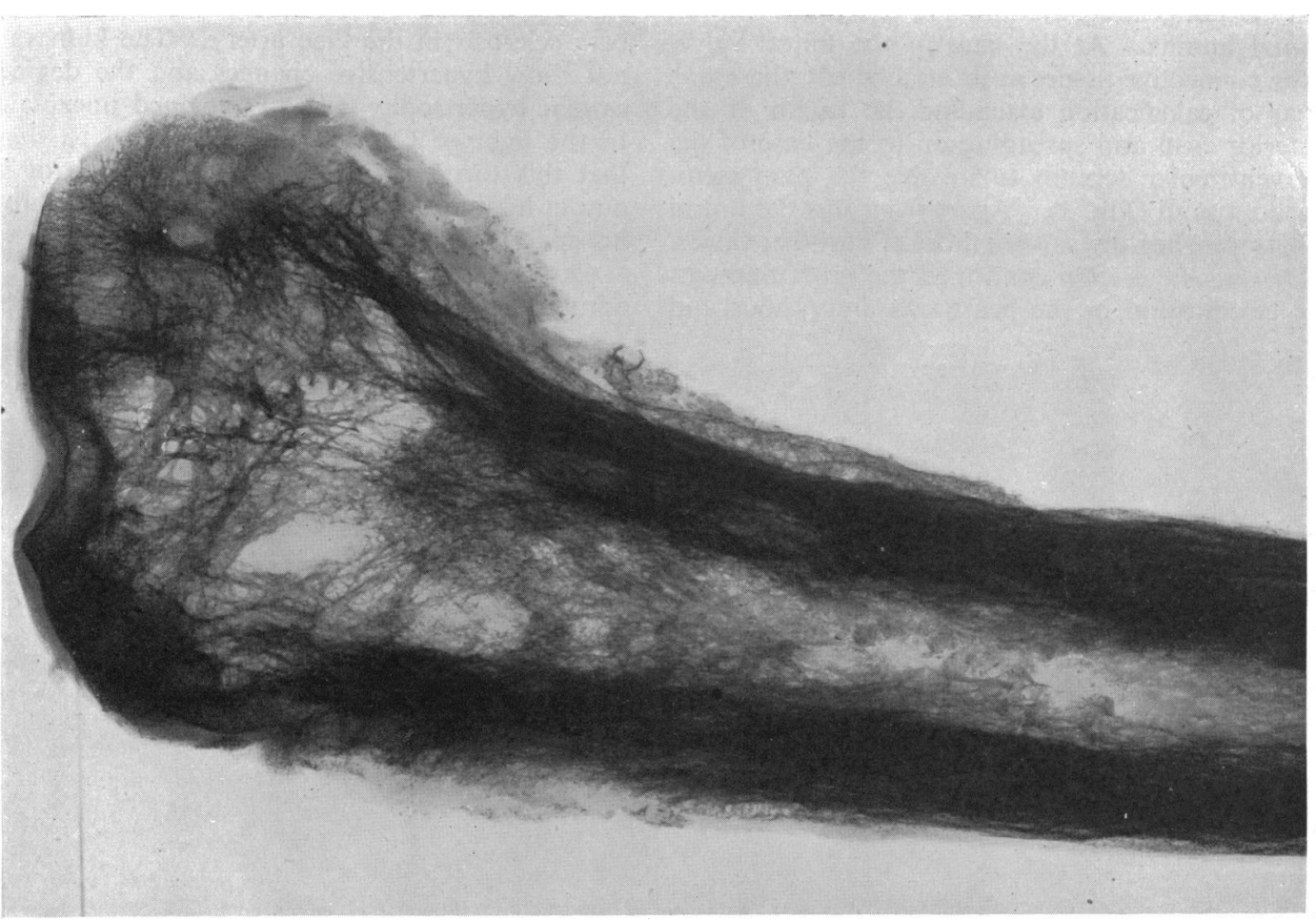

FIG. 4.-Case 2. X-ray of lower end of femur (post-mortem specimen) showing advanced Paget's disease.

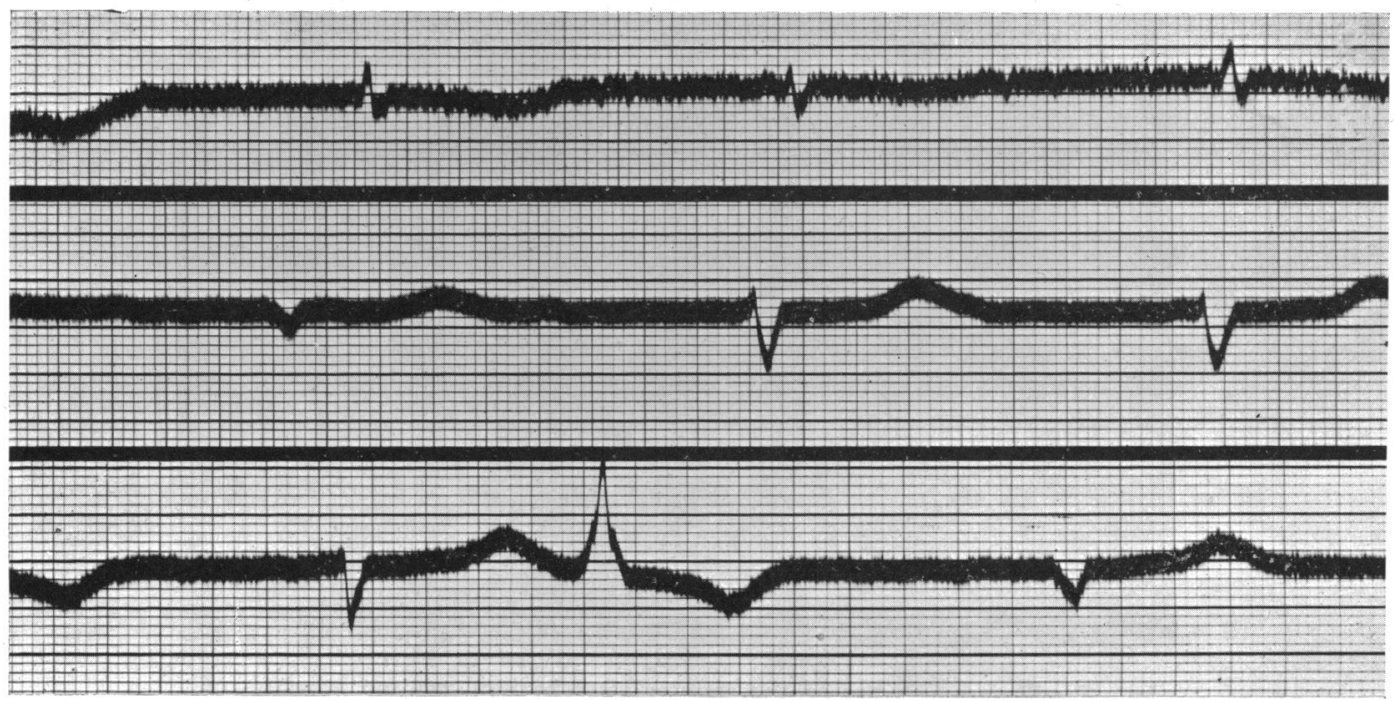

Fig. 5.-Case 2. Electrocardiogram showing complete heart block with ectopic beats. 
J. McMichael. A known case of Paget's disease for many years he had been bedridden for 2 to 3 years. There had been dyspnœa, orthopnœa, and mental changes for three weeks, and odema for one week. On examination, there was orthopnœa, widespread œdema, an.enlarged tender liver, fluid at the right base, and jugular venous pressure $10 \mathrm{~cm}$. above the sternal angle. The skeleton showed gross deformity of the skull, limbs, and clavicle: radiographs confirmed extensive Paget's disease (Fig. 4) and showed also extensive arterial calcification. Pulse rate, 34; B.P. 120/60. Apex beat four and a half inches to left of midline. A blowing systolic murmur over whole præcordium. A cardiogram (Fig. 5) showed complete block with coupled ectopic beats (Dr. Paul Wood). Alkaline phosphatase 132 units (KingArmstrong). Blood urea $54 \mathrm{mg}$., bilirubin $1.5 \mathrm{mg}$. each per $100 \mathrm{ml}$. Cardiac catheterization was only partially successful, but an abnormally high oxygen content of the venous blood, especially in the jugular vein, was demonstrated. Treatment of the cardiac failure proved ineffective and he died on Nov. 3, 1947, twelve days after admission.

Autopsy was carried out 11 hours after death. The skeletal changes of Paget's disease were gross and typical, involving the cranium, all bones of the trunk, and all long bones except the fibulæ.

Microscopically the bone changes were typical and indicated widespread activity (Fig. 6). Vascu-

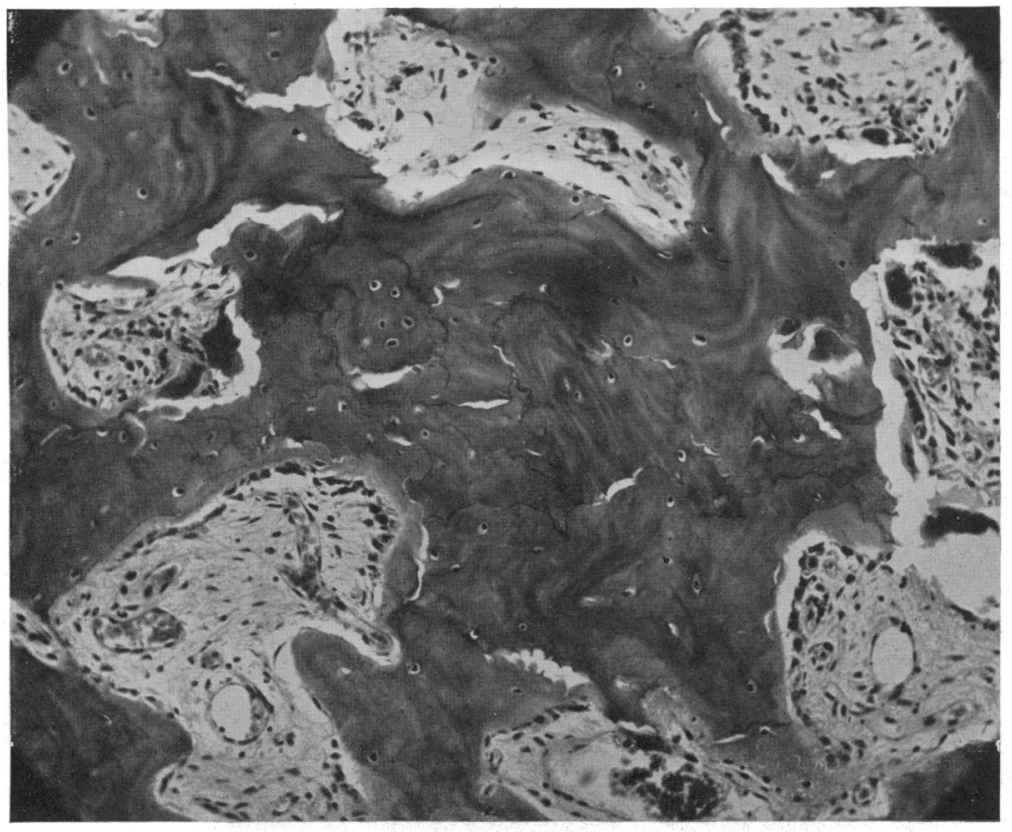

FIG. 6.-Case 2. Rib, showing active Paget's disease. Stained with H. and E. Magnification: $\times 112$. larity was obvious both macro- and microscopically. The heart weighed $435 \mathrm{~g}$.: there was moderate hypertrophy of both left $(1.8 \mathrm{~cm}$.) and right $(0.7 \mathrm{~cm}$.) ventricles. The posterior mitral cusp was contracted into a solid calcified ball: all cusps of the aortic valve, with both the aortic and the mitral rings, were thickened and patchily calcified: the process had extended into the upper posterior twothirds of the membraneous septum. The extent of the lesions is best seen in an X-ray of the specimen (Fig. 7). The anterior descending coronary branch was blocked near its origin and the block calcified, but there was no infarct. Histological examination of the heart added little to the naked eye findings: in the region of the calcification the bundle of His was quite unrecognizable, though Purkinje fibres in the muscular septum appeared healthy. There was extensive medial calcification with relatively mild atheroma in arteries everywhere (Fig. 8). Findings in other systems included cystitis and an old pyelonephritic atrophy of the right kidney $(55 \mathrm{~g}$.$) , calcification of the right cupola of$ the diaphragm, and an old collapse of the lower lobe of the right lung. The thyroid, pituitary, and adrenals were normal. The parathyroids were of average size but showed an almost complete absence of oxyphile cells.

\section{Discussion}

Calcification of the heart valves and rings, though often described, has not been shown to be significantly commoner in Paget's disease than in controls of the same age. We have, therefore, collected some data on this point.

Our departmental records contain 13 cases of generalized Paget's disease. Six of their hearts showed valvular calcification (see Table I). To this we have added 30 reported cases. Adequately detailed accounts are rare: most articles are purely clinical (including nearly all the larger series-Gutman and Kasabach, 1936; Newman, 1946; Kay et al., 1934; Sugarbaker, 1940; O'Reilly and Race, 1932; Looser, 1926; and others (especially Schmorl) deal only with the bones. A search of 170 of the readily available articles, 


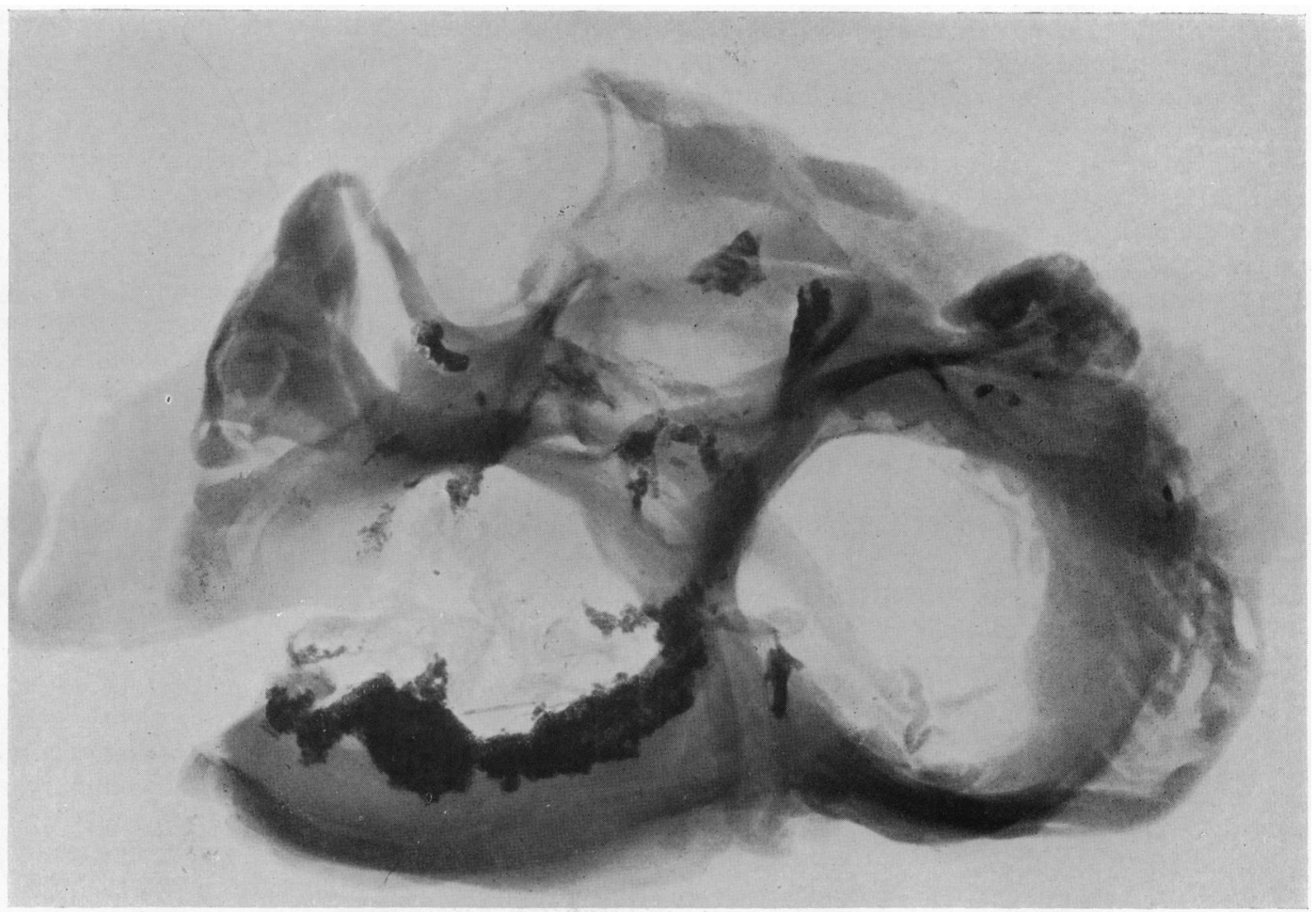

Fig. 7.-Case 2. X-ray of a transverse slice of the heart containing the valves, showing irregular calcification involving especially the posterior part of the mitral ring and extending on to the membranous septum.

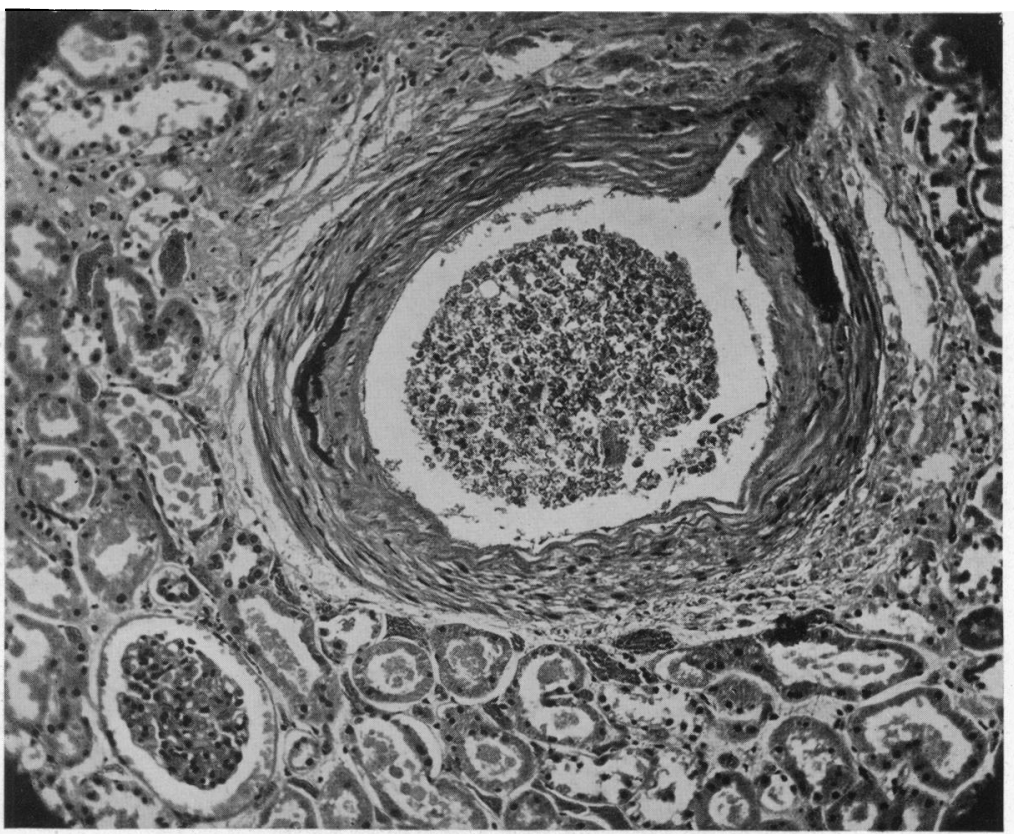

FIG. 8.-Case 2. Left kidney, showing medial calcification in a small artery. Stained with H. and E. Magnification: $\times 112$. 
covering some 820 cases, has yielded only 30 autopsied cases in which the disease was generalized, the diagnosis clear, and the heart either described or reasonably to be assumed normal; several of these showed calcification (Table II). Combining our 13 with the 30 reported cases of Paget's disease we find that 17 out of the 43 (39 per cent) showed valvular calcification. In a control series of 223 autopsies of similar age distribution from our departmental records 17 showed valvular calcification (8 per cent). A more detailed analysis of these figures is shown in Fig. 9, which also gives the figures for non-calcarious valvular sclerosis.

The two tables give details of the cases from which Fig. 9A was constructed. The eleven cases in Table I make, with the 2 already described, a total of 13 seen in twelve years at this hospital among 4300 autopsies $(0.3$ per cent). No special search for the disease had been made during this time and all the cases listed were extensive and unmistakeable: cases with small and doubtful lesions have not been included. It may be mentioned in passing that the absence of oxyphile cells in otherwise normal parathyroids, noted by Davie and Cooke (1937), has been confirmed in four cases of five examined.

In all those cases in Table II where calcification of valves has not been specifically noted it has been assumed absent: but in several of the older cases (e.g. Goodhart's and Silcock's) the wording leaves some room for doubt.

Two conclusions can be drawn from this comparison. Cardiac calcification is about five times as common in Paget's disease as in controls, and the total incidence of valve disease is about the same (the difference between the two sets of figures is statistically significant but in view of the mixed nature of our data this is perhaps not to be relied on). The implication of this is that whilst collagenous sclerosis of the heart valves is fairly common in old people, those with Paget's disease have an exaggerated tendency to calcify. Necrotic tissue or hyaline collagen have a natural tendency to calcify possibly because of their low $\mathrm{CO}_{2}$ tension but in Paget's disease there is evidence of an additional factor in the form of an unduly labile calcium metabolism. Wells and Holley (1942) recorded a case of Paget's disease in which heavy doses of Vitamin D produced fulminating metastatic calcification, and Seligman and Nathanson (1945) recorded a similar but slower result following relatively small doses. Furthermore, Reifenstein and Albright (1944) recorded two cases of Paget's disease in which immobilization by fracture combined with an ordinary hospital milk diet produced a dangerous elevation of blood calcium. This last observation

TABLE I

Personal Cases of Ostertis Deformans

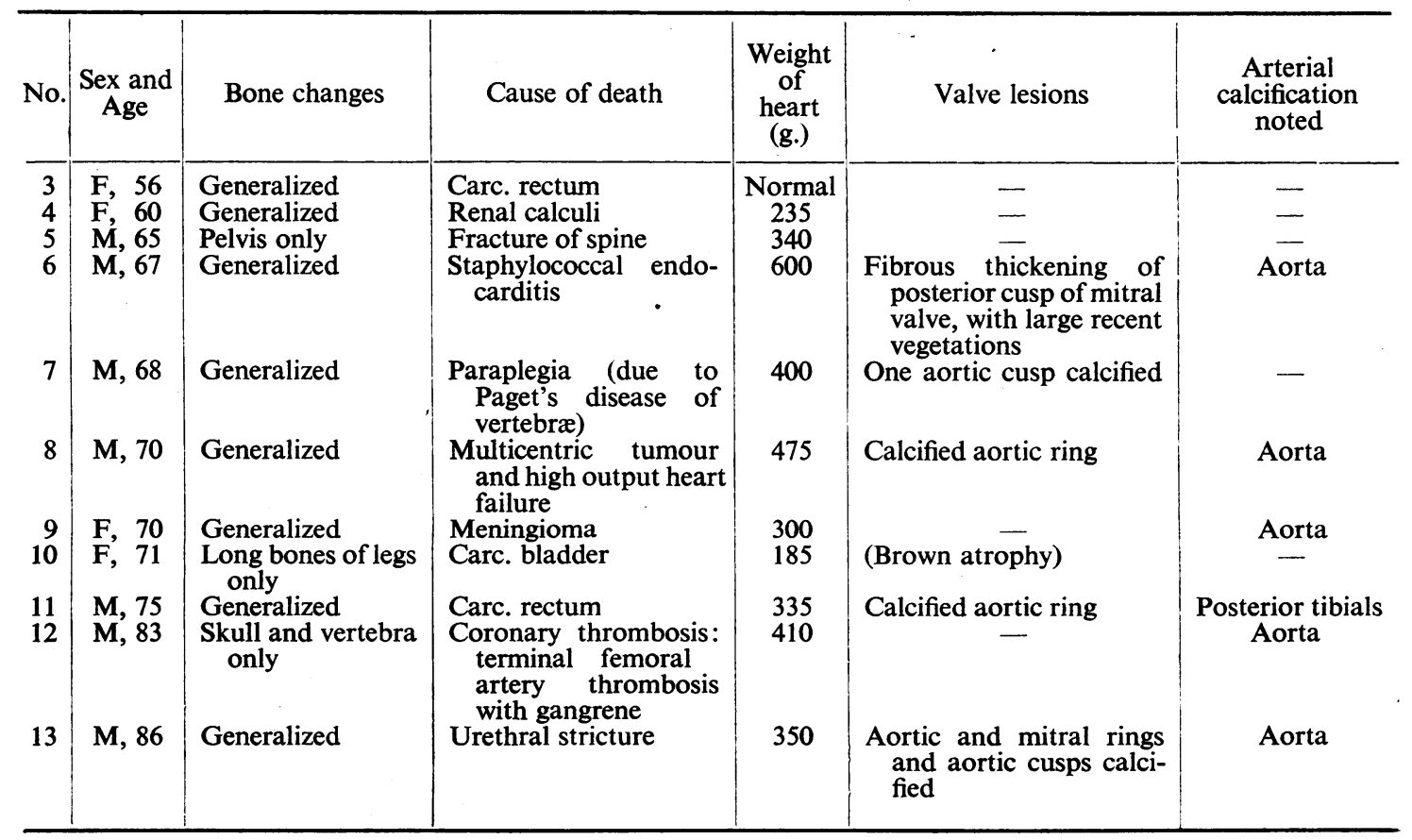


TABLE II

Reported Cases of Osteitis Deformans

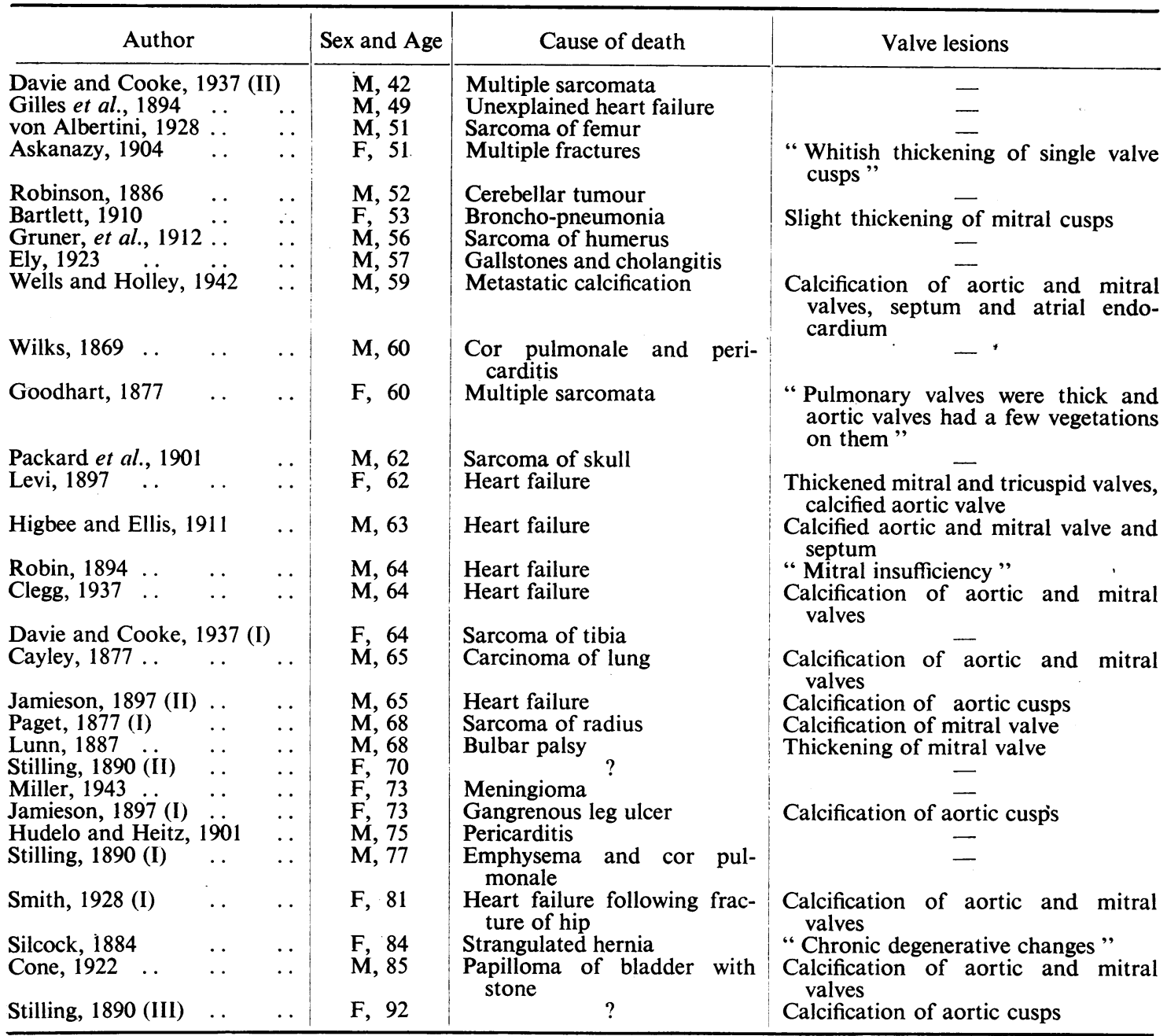

suggests that when Paget's disease is sufficiently crippling to immobilize the patient the risk of metastatic calcification is enhanced-a factor that was present in both of our cases. It seems to us probable that the presence of calcification in the fibrous tissue at the base of the valves may well excite further fibrosis in the neighbourhood and thus become a progressive lesion. This would explain the extension of the process to the membranous septum and justify us in regarding the heart block as a true complication of Paget's disease and not a mere coincidental calcification in a patient with heart block due (a well recognized occurrence) to simple fibrosis. We hope that by drawing attention to these cases we may stimulate a further study that will confirm or refute this.
The Vascular System in Paget's Disease

Vascular disease is extremely frequent in Paget's disease. Any collection of case histories makes this obvious-Kay et al.'s especially well. The vascular lesions have been supposed responsible for the bone disease: Léri (1926) believes the lesions of the nutrient arteries to be responsible, Cone (1933) regards the lesion as a sort of chronic venous congestion of bone. But many of the younger cases show Paget's disease without any vascular lesion (e.g. our Cases 3 to 5 in Table I) and clinically it has often been clearly demonstrated that the heart lesion develops long after the bone lesion (Paget's first case, for instance, also those of Haguenau et al., 1934, and of Thibierge 1893).

The assaults of Paget's disease on the heart and 


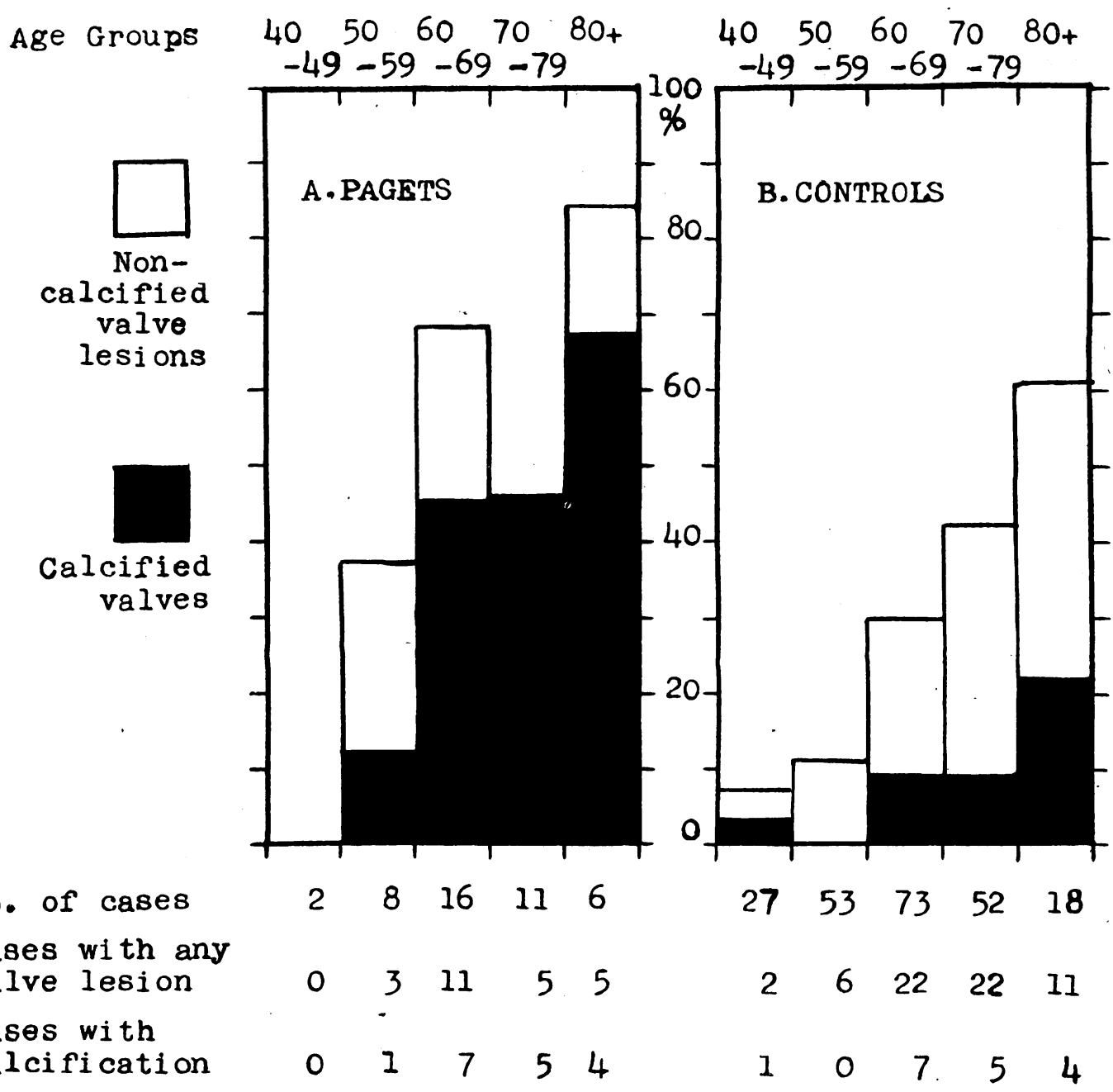

FIG. 9.- The histograms show the percentage incidence by age groups of calcarious and non-calcarious valve lesions in 43 cases of Paget's disease and 223 controls. The actual number of cases is given below.

vessels are various: indeed it is surprising that so many patients reach extreme old age. We believe the principal damaging factors to be as follows.

(a) High cardiac output caused by the shunt through the very vascular bones, implicit in the observations of Redman (1889) on the pulse and of Klippel and Weil (1911) on localized hyperthermia over affected bones, but first clearly demonstrated by Edholm et al. (1945).

(b) Arterial calcification, as first demonstrated radiologically by Béclère in 1901. O'Reilly and Race (1932) found it in 43 per cent of their cases and although they give no control figures they were satisfied that this represents a significant increase above what might be expected in patients of the same age. The finding has been commonly called
" arteriosclerosis "' and might be supposed to consist of either Mönckeberg's sclerosis or calcarious atheroma. Since, however, occlusive vascular disease is certainly not unduly frequent in Paget's disease (there is only one certain arteriosclerotic gangrene in our 820 collected cases and no coronary death in our 43 autopsies) it seems reasonable to assume that the increased incidence of radiological shadows is due to Mönckeberg's sclerosis.

(c) Thoracic deformity producing cor pulmonale. This is surprisingly rare, though one of the earliest cases (Wilks, 1869-which is also Paget's Case 4 of 1877) died in this way, and perhaps also Stilling's Case 1 (1890).

(d) Valve calcifications discussed in this paper.

(e) Heart block. This is perhaps not so rare as 
the lack of reported cases would indicate. Cases of Paget's disease in time join the chronic sick and, though they may be studied well at some stage of their progress, they do not usually die under supervision unless they have a sarcoma or some such dramatic lesion. Heart block in a heart already embarrassed by a high output and calcified valves is probably rapidly fatal: there are quite a number of unexplained heart failures among published cases (Clegg, 1937; Higbee and Ellis, 1911; and S. Paget, 1884) which it is tempting to think may have been fatal Stokes-Adams attacks. With increasing interest in the causes of death in old people more cases may well come to light.

\section{SUMMARY}

Two cases of osteitis deformans are reported in which calcification of the membranous interventricular septum caused complete heart block.

A survey of published papers has revealed only two similar cases but there are reasons for suggesting that this complication may be more frequent than this indicates.

In 30 published and $\mathbf{1 1}$ further personal cases of Paget's disease, calcification in the heart was found to be significantly commoner than in a control series.

Our thanks are due to Professor J. McMichael and Dr. Paul Wood for much help with the clinical aspects of these cases, and to Mr. J. R. Baker and Mr. J. Griffin for the sections and Mr. E. V. Willmott for the photographs used in illustration.

\section{REFERENCES}

Askanazy, M. (1904). Arb. Geb. Path. Anat. Tübingen, 4, 398.

Bartlett, C. J. (1910). Yale med. J., 16, 367.

Cayley, W. (1877). Trans. Path. Soc., 29, 172.

Clegg, J. L. (1937). Lancet, 2, 128.

Coley, B. L., and Sharp, G. S. (1931). Arch. Surg. Chicago, 23, 918.

Cone, S. M. (1922). J. Bone Jt. Surg., 4, 751.

(1935). Ibid., 15, 190.

Da Costa, J. C., Funk, E. H., Bergeim, O., and Hawk, P. B. (1915). Pub. Jefferson Med. Coll. Hosp., 6, 1 .

Davie, T. B., and Cooke, W. E. (1937). Brit. J. Surg., $25,299$.

Edholm, O. G., Howarth, S., and McMichael, J. (1945). Clin. Sci., 5, 249.

Ely, L. W. (1923). Arch. Surg. Chicago, 7, 532.

Gilles de la Tourette, and Magdelaine, L. (1894). Bull. Mem. Soc. méd. Hôp. Paris, 7, 1.

Goodhart, J. F. (1877). Trans. Path. Soc., 29, 175.

Gruner, O. C., Scrimger, F. A. C., and Foster, L. S. (1912). Arch. intern. Med., 9, 641.

Gutman, A. B., and Kasabach, H. (1936). Amer. J. med. Sci., 191, 361.

Haguenau, J., Gully, L., and Daum, -., (1934). Bull. Mem. Soc. méd. Hôp. Paris, 43, 931.

Higbee, W. S., and Ellis, A. G. (1911). J. med. Res., 24, 43.

Hudelo, L., and Heitz, J. (1901). Nouv. iconog. Saltpet., $14,415$.

Jaffe, H. L. (1933). Arch. Pathol., 15, 83.

Jamieson, S. (1897). Aust. med. Gaz., 16, 14.

Karsner, H. T., and Koletsky, S. (1947). Calcific Disease of the Aortic Valve, Philadelphia.

Kay, H. D. (1930). J. biol. Chem., 89, 249.

-, Simpson, S. L., and Riddoch, G. (1934). Arch. intern. Med., 53, 208.

Klippel, - 1228., and Weil, -. (1908). Rev. Neurol., 16,

Knaggs, R. L. (1926). Brit. J. Surg., 13, 206.

Koller, F. (1946). Helv. med. act., 13, 389.

Léri, A. Les affections des os et des articulations. Paris. 1926 (quoted by O'Reilly and Race, 1932).
Levi, L. (1897). Nouv. iconog. Saltpet., 10, 113.

Looser, E. (1926). Schweiz. med. Wschr., 7, 598.

Lunn, J. R., (1887). Trans. Path. Soc., 39, 265 (repeated in Ill. Med. News, 2, 182, 1889).

Miller, J. (1943). Canad. med. Ass. J., 49, 13.

Moehlig, R. C., and Adler, S. (1937). Surg. Gynec. \& Obstet., 64, 737.

Newman, F. W. (1946). J. Bone Jt. Surg., 28, 798.

O'Reilly, J. J., and Race, J. (1932). Quart. J. Med., 25, 471.

Packard, F. A., Steele, J. D., and Kirkbride, T. S. (1901). Trans. Ass. Amer. Phys., 16, 666.

Paget, J. (1877). Med. chir. Trans., 60, 37. 29, 1936).

- (1889). Ill. Med. News, 2, 181.

Paget, S. (1884). Trans. Path. Soc., 36, 382.

Redman, W. E. (1889). Ill. Med. News, 2, 189.

Reifenstein, E. C., Jr., and Albright, F. (1944). New Engl. J. Med., 70, 295.

Robin, A. (1894). Nouv. Iconog. Saltpet., 7, 15.

Robinson, A. H. (1886). Trans. Path. Soc., 38, 262 (repeated Lancet, 1, 826, 1887).

Schmorl, G. (1926). Verh. dtsch. path. Gesh., 21, 71.

- (1930). Ibid., 25, 205.

(1932). Virchows Arch., 283, 694.

Seligman, B., and Nathanson, L. (1945). Ann. intern. Med., 23, 82.

Silcock, A. Q. (1884). Trans. Path. Soc., 36, 383 (repeated Brit. med. J., 1, 595, 1885, and Lancet, 1, 519, 1885).

Smith, L. H. (1928). J. Nerv. ment. Dis., 68, 578.

Stilling, H. (1890). Virchows Arch., 119, 542.

Sugarbaker, E. D. (1940). Amer. J. Surg., 48, 414.

Thibierge, - (1893). Bull. Mem. Soc. méd. Hôp. Paris, 3rd $S ., 10,116$.

von Albertini, A. (1928). Virchows Arch., 268, 259.

Wells, H. G., and Holley, S. W. (1942). Arch. Pathol., 34, 435 .

Wilks, S. (1869). Trans. Path. Soc., 20, 273.

Windholz, F., and Grayson, C. (1947). Amer. J. Roentgen., 58, 411. 